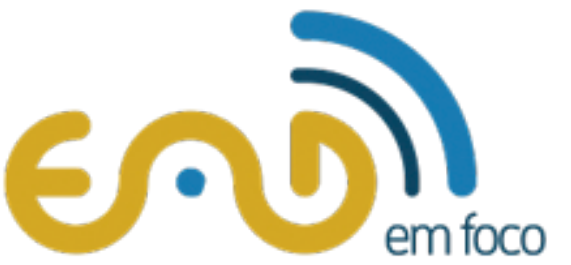

Revista Científica em Educaçăo a Distância

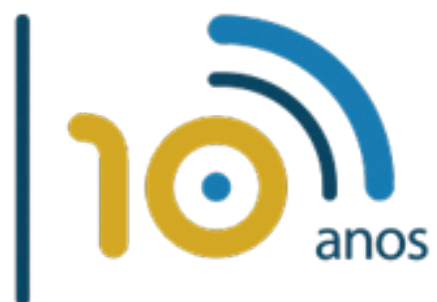

\title{
Desenvolvendo Cursos de Formação Inicial e Continuada (FIC) EaD em Regime de Trabalho Remoto: Relato de
} Experiência

\section{Developing Initial and Continuous Education E-lea} Courses in Remote Work: Experience Report

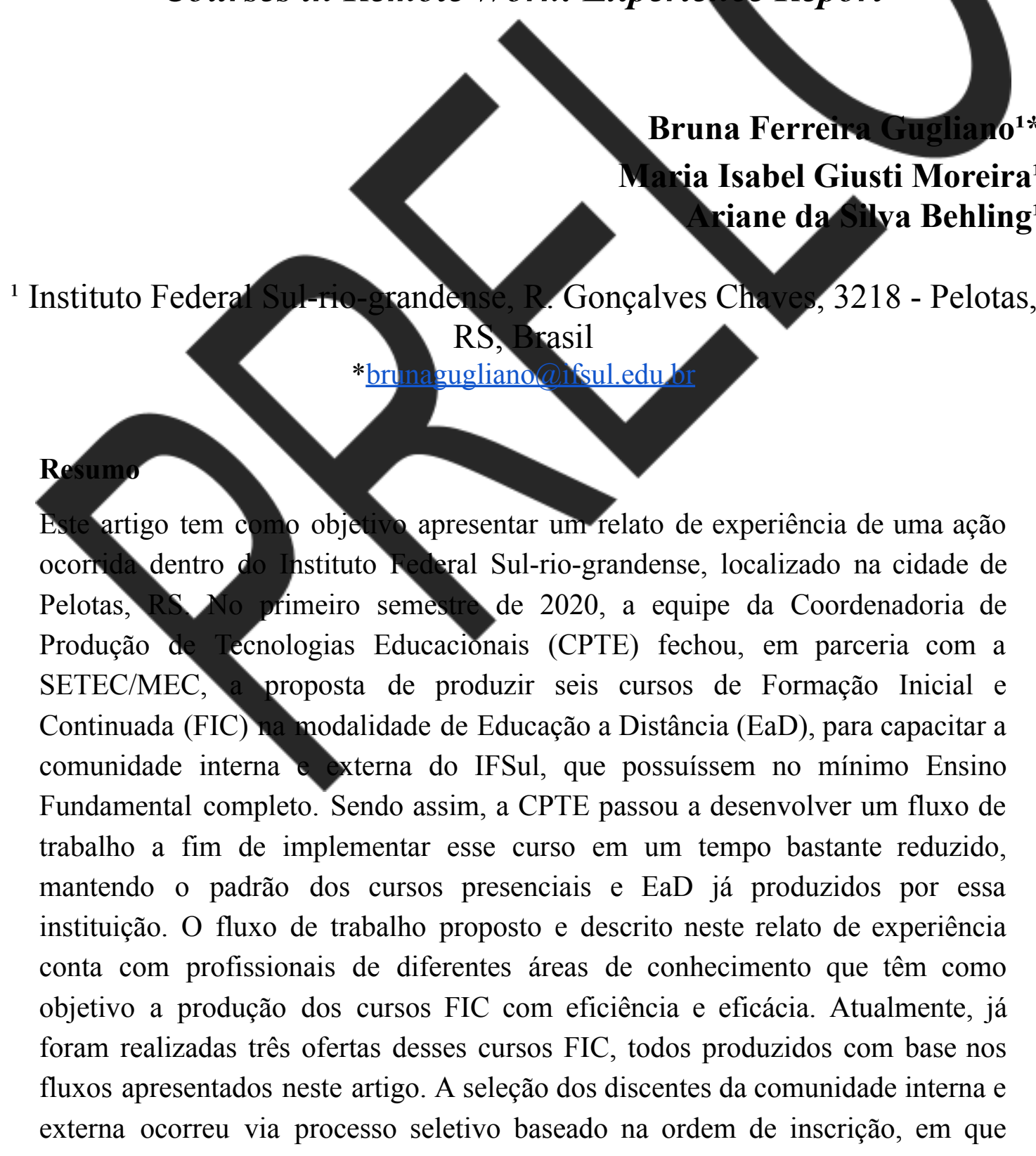




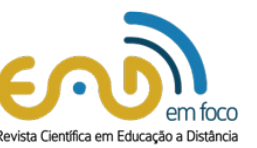

foram ofertadas 80 mil vagas, divulgadas nas redes do IFSul. Ao final da primeira oferta dos cursos FIC, concluíram o curso em torno de 40 mil alunos e pôde-se avaliar e validar os cursos produzidos com a comunidade.

Palavras-chave: Formação inicial e continuada. EaD. Fluxo de trabalho. Cursos MOOC.

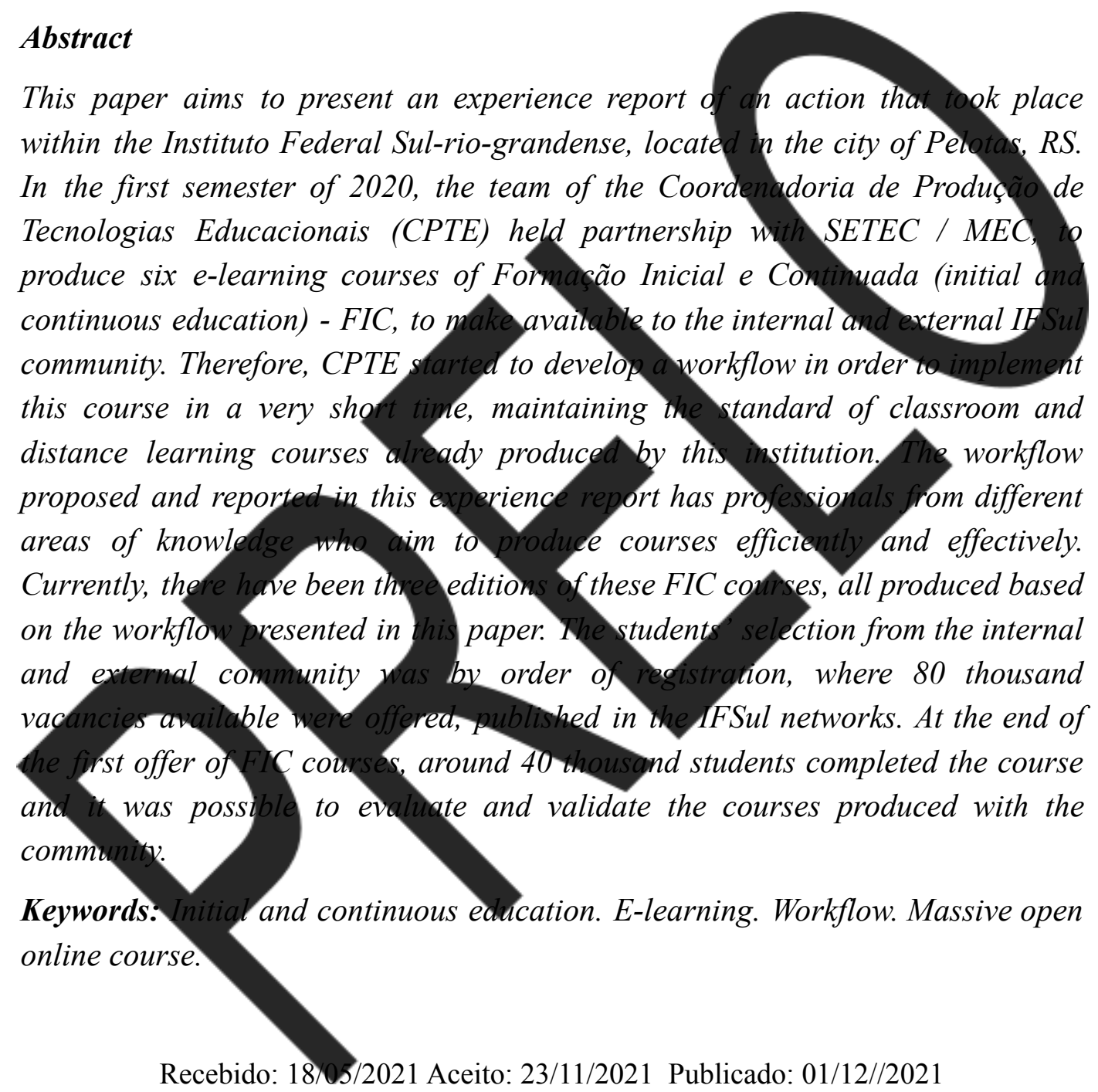

\section{Introdução}

A Educação a Distância (EaD) é uma modalidade de ensino efetivada através da utilização das Tecnologias Digitais de Informação e Comunicação (TDIC), permitindo, através dessas tecnologias, a oportunidade de alunos de diferentes faixas etárias e lugares estudarem e/ou se atualizarem.

De acordo com o Ministério da Educação (2021, sp), 
Educação a distância é a modalidade educacional na qual alunos e professores estão separados, física ou temporalmente e, por isso, faz-se necessária a utilização de meios e tecnologias de informação e comunicação. Essa modalidade é regulada por uma legislação específica e pode ser implantada na educação básica (educação de jovens e adultos, educação profissional técnica de nível médio) e na educação superior.

Segundo Moran (2002), a Educação a Distância pode ser utilizada para o processo de ensino e aprendizagem em diferentes níveis de ensino, como fundamental, médio, superior e a pós-graduação. Desde 2009, o Instituto Federal Sul-rio-grandense (IFSul) vem ofertando cursos $\mathrm{EaD}$ desses diferentes níveis de ensino, como cursos técnicos subsequentes, graduação e pós-graduação.

No final do ano de 2019, surgiu no mundo uma nova doença pertencente a una família do vírus CoronaVírus $(\mathrm{CoV})$. Esse novo coronavírus recebeu a denominação SARS-CoV-2 pela Organização Mundial da Saúde (OMS) e doença que ele provoca tem a denominação COVID-19. Diversas áreas, como da saude e financeira, estão enfrentando novos desafios impostos por esșa doença. Com a área daEducação não foi diferente: de acordo com as Nações Unídas, empouco mais de três semanas, cerca de 1,5 bilhão de estudantes em pelo menos 174 países ficaram fora da escola e da universidade em todo o mundo (MUNOZ, 2020)
Sentindo a necessidade de-oportuniza uma ocupação e monentos de estudo para esses
alunos que estavam longe dos espaços de aprendizagem, o IFSul resolveu propor uma alunos que estavam longe dos espaços de aprendizagem, o IFSul resolveu propor uma
alternativa de estudos baseado nos conceitos de Educação a Distância e de Cursos Online Abertos e Massivos (em ing ês, MOQC Massive Open Online Courses), visto
que os potos-presenciais, escolas e universidades estavam fechados. Chauan et al (2015), define os MOOC como cursos disponibilizados por meio da Internet, sem custo, oferecidos para un númèro grande de pessoas Com essa grande abrangência, a modalidade pode permitir o acesso de conteúdos que auxiliem o desenvolvimento de uma formação profíssional e cidadã, estimulando a entrada no mundo do trabalho e geração de r

Assim, e de acordo com Cohen e Holstein (2018), os cursos MOOC possuem uma dimensão social, pois permitem conectar muitos alunos que podem interagir e se apoiar, de modo a fornecer ou buscar suporte no aprendizado, discutir os conteúdos e compartilhar interesses em comum.

Para Ribeiro e Catapan (2018), no Brasil, os MOOC avançam num ambiente diferenciado do cenário educacional de outros países, em especial, dos países chamados desenvolvidos. Nesses países - como, por exemplo, os Estados Unidos - os cursos são comercializados por empresas privadas, como Udemy e Coursera, que não possuem restrição em sua atuação. Já no Brasil, a EaD é regulada e incentivada por recursos públicos, o que possibilita uma distribuição mais democrática dos conteúdos. Da mesma maneira, os cursos produzidos pelo IFSul vêm com uma proposta inovadora, 


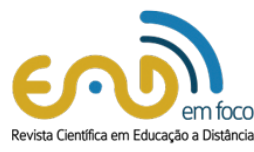

trabalhando exclusivamente cursos baseados em videoaulas curtas e questões com autocorreção, de fácil acesso, utilizando a plataforma livre e gratuita Moodle.

Esse artigo tem como objetivo relatar e compartilhar a experiência realizada na produção de seis cursos FIC EaD, no formato MOOC: Assistente Administrativo, Assistente de Controle de Qualidade, Gestor de Microempresa, Montador e Reparador de Computador, Operador de Computador e Programador Web, apresentando os processos realizados.

\section{Contextualização}

No primeiro semestre de 2020, a equipe da Coordenad Educacional (CPTE), pertencente ao Departamento de Educação a Distância - Novas Tecnologias (DETE) do Instituto Federal Sul-rio-grandense (IFSul), localizado na região sul do Rio Grande do Sul, recebeu a demanda de produzir seis cursos de Formação Inicial e Continuada (FIC), na medalidade de Educação a Distância (EaD), para disponibilizar para a comunidade interna e externa do IFSul.

De acordo com o MEC (2021), os garsos FIC têm o objetivo de preparar os estudantes para o mercado de trabalho e promover o aperfeiçoamento da população em todos os níveis de escolaridade. De acordo con o Regulamento de Funcionamento dos cursos de extensão Livres e/ou de Formação Inicial e Continuada ou Qualificaçáo Profissional do IFSul (IFSUL, 2016) os FIC são considerados cursos de gualificação profissional não vinculados ao ensino regular e podem ser criados de acordo gom demandas percebidas na sociedade $\mathrm{O}$ mesmo documento, no primetro parágrafo do artigo $5^{\circ}$, estabelece: " $\$$ $1^{\text {o }}$ - Esses cursos têm como finalidade promover a inserção profissional no mundo do
trabalho, por meio do desen olvimento de aptidões para a vida produtiva e social"
(IFSUL, 2016, p. 2).

Como já citado, a proposta feita pela Equipe de Coordenação da CPTE foi de produzir esses cursos FIC na modalidade MOQC, o que fez com que fosse necessário repensar a forma em que os conteúdos seriam organizados e estruturados. Dessa forma, ficou estabelecido que a conteúdo a ser produzido seria desenvolvido com base em videoaulas de curta duração e na realização de atividades de múltipla escolha, para permitir que o aluno tivesse a autonomia de escolher seus horários de estudo, propiciando maior flexibilidade nesse período acometido pela pandemia. A iniciativa é apoiada pela Portaria MEC no 343, de 17 de março de 2020, que permite a substituição das aulas presenciais por aulas em meios digitais enquanto durar a situação de pandemia do novo coronavírus - COVID-19.

Como suporte aos cursos, a equipe da CPTE realizou a customização de um Ambiente Virtual de Aprendizagem (AVA), em relação às questões de usabilidade, acessibilidade e 
responsividade $^{1}$. Estes aspectos são essenciais para um bom uso das plataformas, já que possíveis dificuldades com as ferramentas podem afetar a experiência de aprendizagem do usuário (NAKAMURA; OLIVEIRA; CONTE, 2017). Assim, os estudantes podem acessar os cursos em dispositivos digitais, sendo um computador, tablet, smartphone, entre outros, sem haver prejuízo na experiência de uso da plataforma e na compreensão de seus conteúdos. Outra questão importante era a acessibilidade dos cursos, para que fosse possível atender ao maior número de estudantes, como previsto no Art. 17 da Lei $\mathrm{n}^{\mathrm{o}}$ 10.098, de 19 de Dezembro de 2000 (Lei da Acessibilidade) que promove a eliminação de barreiras na comunicação e na educação para as pessoas portadoras de deficiência. Por este motivo e de acordo com as capacidades técnicas disponíveis, a equipe da CPTE definiu que todas as videoaulas deverian conter interpretação de libras. Para auxiliar na criação desses cursos - que tinham o prazo de apenas três meses para seu desenvolvimento de todo o material e publicação - foram lançados seto editais (IFSUL, 2020), com o objetivo de contratar os profissionais nocessários para a criação e publicação dos conteúdos de cada disciplina. Desta forma, foi priginada uma equpe multidisciplinar de múltiplos saberes, contando com, aproximadamente, 180-membros, divididos em Coordenadores (as) decurso e de polo; Professores (as) mediadores (as); Professores (as) conteudistas; Designers instrucionais; Revisores (as) pedagógicos (as); Revisores (as) lingüísticos (as), Designers gráicos (as); Editores (as) de vídeo; Intérpretes de Libras, Desenvolvedores (as) Web e Suporte de T1; Pesquisadores (as) e equipe de permanência êxito, Atxiliaros financeiros e administrativos.

A produção precisot ser feita no regime de trabalho remoto, devido à crise sanitária de COVID-19,-aque lovantou vártas hecessidades deadequações no fluxo de trabalho já existente na-GPTK Consideraram-se alguns fatores, entre eles, o prazo reduzido, o trabalho colaborativo, as difictudades com o uso das tecnologias digitais ${ }^{2}$, as limitações das formas de comuniçação (agora, totalmente a distância) e os possíveis percalços enfrentados pelos integrantes da equipe ao produzir em casa, em um ambiente que poderia não ser próprio para o trabalho intelectual.

Para auxiliar nesse processo, algumas medidas tomadas foram: capacitar para o uso das ferramentas digitais (Google Drive, Trello e Slack), dividir a equipe por cursos e disciplinas, disponibilizar templates para inserção dos conteúdos, comunicar de forma redundante (repetir as notificações e mensagens em diversas plataformas), capacitar sobre especificidades e termos técnicos de cada área e capacitar sobre a gravação de videoaulas e criação de apresentações de slides, gráficos e figuras. A Figura 1 apresenta um template de apresentação de slides, criado para auxiliar na padronização dos materiais e guiar os(as) conteudistas quanto aos espaços a serem utilizados.

\footnotetext{
${ }^{1}$ Qualidade da interface que se adapta a diversos tamanhos de tela.

2 Por exemplo, falta de capacidade de processamento de computador, não saber gravar um vídeo ou não dominar a utilização das plataformas de trabalho colaborativo
} 

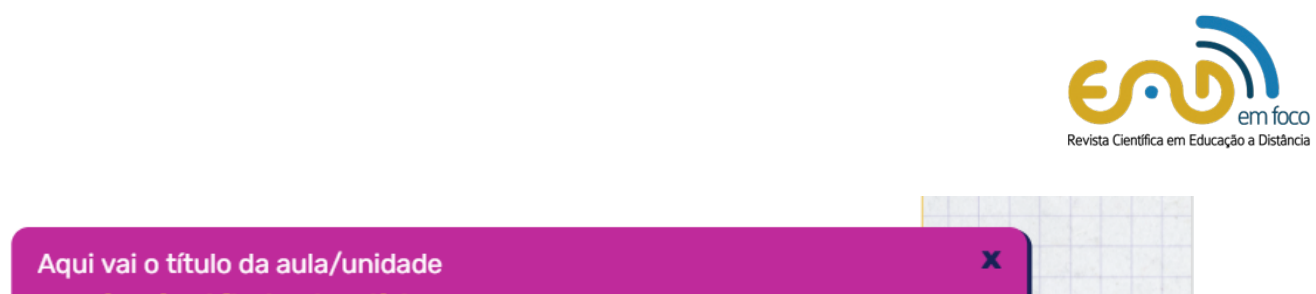

Aqui vai o título do slide

Use esta área demarcada para posicionar imagens.

Não esqueça a fonte para a imagem, e se for preciso

use legenda.

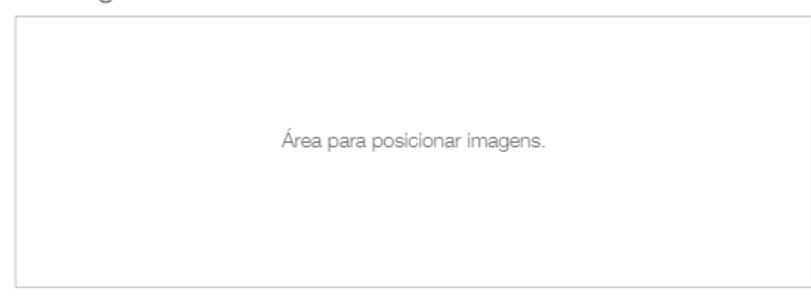

Fonte: Para a fonte, coloque o link para a imagem. Use um encurtador como o bitly.com

Aqui vai a legenda da imagem

Figura 1. Template de apresentação de slides de um dos cursos.

Pensar em um fluxo de trabalho

Fonte: as autoras se adéque às necessidades proy mita o

deamento de váriı

entes da situaçà pandêmica vigente demanda uma visão sistêmica de todas as etâpas de um projeto educacional. Uma abordagem sistêmica permite a resolução de problemas a partir da visâo do todo (NETO, 2017), compreendendo as relações entre as otapas, as inplicações entre uma e outra e as tarefas necessárias.

\section{Referencial teorico}

A Educação a Distâncià

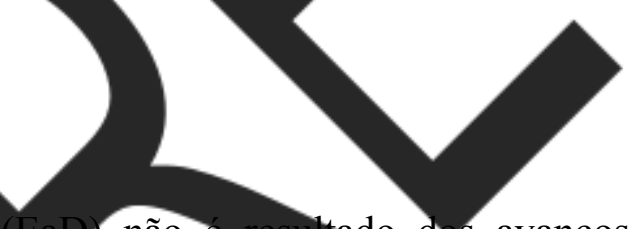

ca1) não é resultado dos avanços tecno mesmo antes da intenção dos computadores, ousos inteiros eram ministrados através de liçöes enviadas por correio, existindo, inclusive, um conselho Internacional de Educação por Correspondência, o ICCE (International Council for Correspondence Education), fundado em 1938. Em 1982, esse mesmo conselho atualizou seu nome para International Council for Distance Education (HACK, 2011), popularizando a expressão 'Educaçẫo a Distância' para a comunidade em geral. No Brasil, foi o decreto nº 2.494, de 1998, que definju Educação a Distância como

(...) uma forma de ensino que possibilita a auto-aprendizagem, com a mediação de recursos didáticos sistematicamente organizados, apresentados em diferentes suportes de informação, utilizados isoladamente ou combinados, e veiculados pelos diversos meios de comunicação. (BRASIL, $1998, \mathrm{~s} / \mathrm{p})$.

A primeira lei brasileira a citar a educação na modalidade a distância foi a Lei de Diretrizes e Bases da Educação de 1996, que em seu 80 artigo, estabelece: “Art. 80. O Poder Público incentivará o desenvolvimento e a veiculação de programas de ensino a distância, em todos os níveis e modalidades de ensino, e de educação continuada" 
(BRASIL, 1996, p. 29), sendo atualizada e normatizada posteriormente por outros decretos (ORTH; OTTE; MEIRELES, 2014).

Para fornecer esse incentivo, cabe citar dois grandes programas de governo que contribuíram para o avanço da EaD no Brasil: o programa Universidade Aberta do Brasil (UAB), criado em 2005 pelo então Ministério da Educação para ofertar cursos superiores e capacitações a professores da educação básica e a Rede e-Tec Brasil, lançada em 2007 com o objetivo de ampliar a oferta da EPT (Educação Profissional e Tecnológica) a distância (CRUZ; LIMA, 2019).

Além dos diversos marcos regulatórios da $\mathrm{EaD}$ no programa de credenciamento e recredenciamento das in distância. Este sistema analisa diversos indicadores, como a existência de planos de gestão de sistemas e acadêmica, o funcionamento de unidade exclusitą para a organização da $\mathrm{EaD}$ e a produção de material didático, progtamas de capacitacâa de professores e mediadores, infraestrutura, entre outros (SILVA,

Com o avanço das Tecnologias

ensino na modalidade a distâne

de

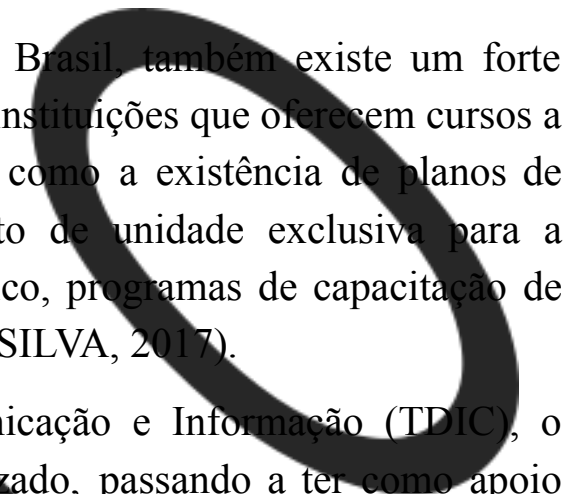
diversos suportes digitais e, portanto, agregando novas interfaces que conduzem a distintas experiências na construção do aprendizado. Da mesma forma, os métodos para a produção de materiais didáticos precisaram de reformulação. Diante desse cenário, aumentam as pesquisas sobre a EaD, como afirmam Alonso e Sil

(...) das en formativos, presencia-se, nos tiltimos anos, vertiginosa expansão da oferta de

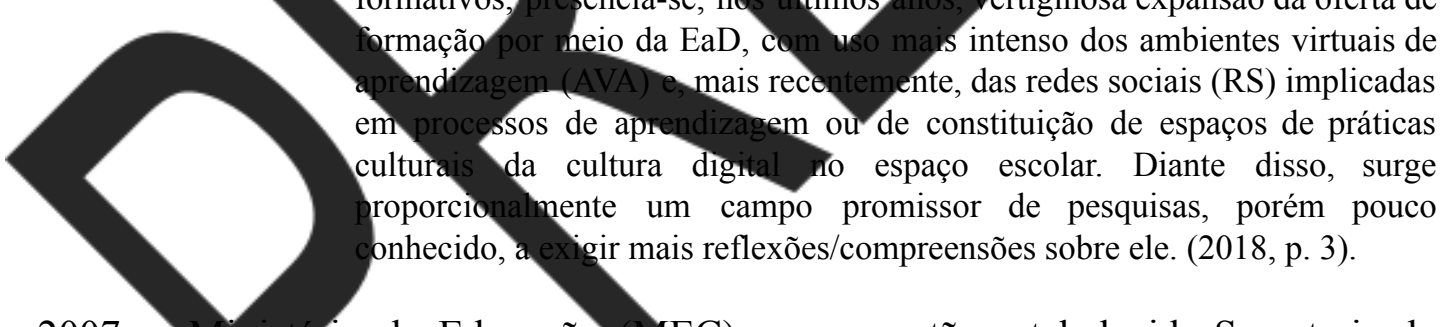

Em 2007, o Ministério da Educação (MEC), com a então estabelecida Secretaria de Educação a Distância, publicou o documento "Referenciais de Qualidade para Educação Superior a Distância" (BRASIL, 2007). Os referenciais tinham como objetivo atualizar o primeiro texto lançado pelo MEC, em 2003, a partir das

(...) alterações provocadas pelo amadurecimento dos processos, principalmente no que diz respeito às diferentes possibilidades pedagógicas, notadamente quanto à utilização de tecnologias de informação e comunicação, em função das discussões teórico-metodológicas que têm permeado os debates acadêmicos. (BRASIL, 2007, p. 3).

O documento salienta a importância de os Projetos Políticos Pedagógicos (PPPs) dos cursos a distância conterem no mínimo oito tópicos principais (BRASIL, 2007, p. 8):

- Concepção de educação e currículo no processo de ensino e de aprendizagem; 
- Sistemas de Comunicação;

- Material didático;

- Avaliação;

- Equipe multidisciplinar;

- Infraestrutura de apoio;

- Gestão Acadêmico-Administrativa;

- Sustentabilidade financeira.

No item 'Material didático', os autores e as autoras dos a importância de adequação dos materiais usados n adequação deve ser realizada pelos professores em conjunto com uma equipe multidisciplinar, que irá utilizar os conhecimentos nas áreas de design instrucional, design gráfico e web design para adaptar os materiais didáticos às plataformas em que serão inseridos (BRASIL, 2007).

De acordo com Mercado (2018), refere a um grupo de diversos profissionais, com formação específica, reunidos para prestar apoio não somente aoß docentes, mas também às coordenações pedagógicas e dos próprios cursos, que não necessariamente possuem fluência nas linguagens digitais. Num momento como o de pandemia, a importância desse tipo de equipe torna-se ainda mais evidente, considerando que as professoras e os professones se encontram em processo de aperfeçcoamento na utilizaçẫo de ferramentas e tecnologias digitais com relação a métodos estratégiás pedagógicas (SANCHOTENE et al., 2021). Desse modo, os profissionais podem contribuir para e andamento dos cursos de forma significativa apresentando uma aprendizagem motivadora, possibilitando a exploração das mais diversas forramentas emídias digitais, realizando a interação com discentes, contribuindo para evitar a evasão mantendo o êxito no processo. Por tanto, essa definição vại ao encontro da realizada pela Recomendação, que aponta:

A atuação desses profissionais, nas salas de coordenação dos cursos ou nos centros de educação a distância das instituições, tem como principais atribuições o auxílio no planejamento do curso, o apoio aos professores conteudistas na produção de materiais didáticos em diversas mídias, bem como a responsabilidade pelo suporte e desenvolvimento dos sistemas de informática e suporte técnico aos estudantes. (BRASIL, 2007, p. 23).

Percebe-se, aí, uma grande diferença entre o material produzido para a educação presencial e o para a distância: enquanto o primeiro é, normalmente, desenvolvido inteiramente pelo professor, a gestão do segundo pode envolver muitos profissionais, resultando em um esforço coletivo desde a sua concepção até a publicação do material online (BUENO; PASCHOALINO, 2018). Dessa forma, muito do que ocorre de forma pontual, 'ao acaso', em uma sala de aula presencial, deve ser planejado antecipadamente, pois o estudo pode estar sendo feito de forma independente pelo 
estudante na modalidade a distância. Isso exige uma maior atenção na criação dos conteúdos e das atividades por parte do educador, além de uma flexibilidade em relação aos ajustes que podem ser solicitados pelo resto da equipe (MUNHOZ, 2016).

Se o educador é o único à frente de um projeto - como ocorre no caso dos modelos de produção artesanais - , tudo está implícito e é tratado de forma menos ou mais intuitiva. Se, porém, a produção for levada adiante por uma equipe, torna-se imprescindível desenvolver uma visão integrada do que está acontecendo. (FILATRO; CAIRO, 2015, p. 127).

Essa complexidade exige uma gestão estratégica do processo de desenvolvimento dos materiais para a EaD. Para Behr e Mill (2018), consecutivas a fim de atingir determinados objetivos, contexto da $\mathrm{EaD}$, tem como propósito melhorar os tesultados do onsino e da aprendizagem. Os autores apontam cinco conceitos essenciais para gerenciar de forma estratégica (p. 304):

1. Conjunto de decisões: conhecer e se aprofundar em todas as variáveis para tomar decisões encadeadas, que impactam todas as etapas do processo e seus participantes;

2. Atores: vislumbrar quem são os atores envolvidos na EaD, sejam eles pessoas, organizações ou tecnologia

3. Recursos: eficiente;

4.

Objetivos: traçar os resultados tangíveis ou não - que se desejam alcançar e

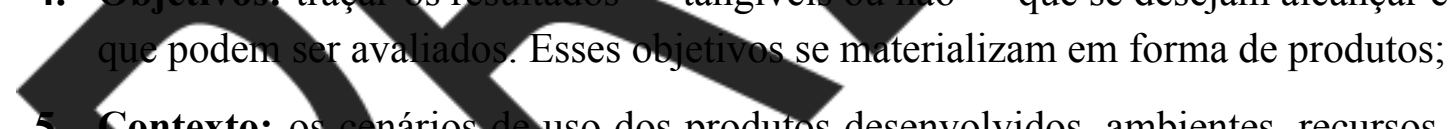

5. Contexto: os cenários de uso dos produtos desenvolvidos, ambientes, recursos, tecnologias e como estes influenciam os indivíduos.

Dessa forma, considera-se importante colocar esses fatores em evidência no momento da criação de um modelo de fluxo de trabalho. Na estrutura formada pela Coordenadoria, cabe aos designers instrucionais pensar em uma sequência de atividades que respeite as possibilidades da equipe, o cronograma disponível e as necessidades do público-alvo: os estudantes

De acordo com Melques (2017), a profissão “designer instrucional” (DI) surgiu durante a Segunda Guerra Mundial com o objetivo de estruturar as forças armadas americanas. Porém, somente nas últimas décadas, com o crescimento da $\mathrm{EaD}$, é que a mesma passou a ser consolidada. O papel do DI é ser responsável pelo planejamento, implementação, avaliação, coordenação e desenvolvimento de projetos pedagógicos e instrucionais. Este processo será apresentado no próximo tópico. 


\section{Resultados}

No caso da produção dos cursos FIC EaD, como uma forma de estabelecer uma métrica, mantendo o padrão entre os módulos das disciplinas de todos os cursos, foi criado, pela equipe de designers instrucionais (DI), um esquema para ser utilizado como guia pelos professores conteudistas, apresentado no Quadro 1. O guia considera o conteúdo produzido versus o tempo que o ou a estudante levaria para acessá-lo ${ }^{3}$, pensando em possíveis pausas ou interrupções no estudo e, para as atividades avaliativas, no tempo levado para retornar ao material em busca das respostas.



O fluxo de trabalho da equipe multidisciplinar iniciava com o professor conteudista em conjunto com o coordenador de curso. A eles cabe definir a matriz curricular, baseada

\footnotetext{
${ }^{3}$ Estimativa baseada em análise de $\log s$ de acessos de estudantes EaD, extraído do Ambiente Virtual de Aprendizagem Moodle.
} 
no Projeto Pedagógico do Curso (PPC), escrever roteiros, atividades pedagógicas ${ }^{4}$ e criar as apresentações de slides do primeiro módulo. Após finalizado, o designer instrucional revisa o conteúdo e sua adequação ao guia elaborado (Quadro 1), solicitando ou realizando as alterações necessárias e repassando ao revisor(a) pedagógica(a) e ao revisor(a) linguístico(a) selecionados(as) para trabalhar com a disciplina. A Figura 2 apresenta um exemplo de como as atividades avaliativas deveriam ser redigidas. Neste exemplo, cabe ao DI revisar os pontos apontados: se o enunciado inclui uma instrução, se as alternativas possuem tamanhos similares ${ }^{5}$ e se a alternativa correta está destacada em negrito.

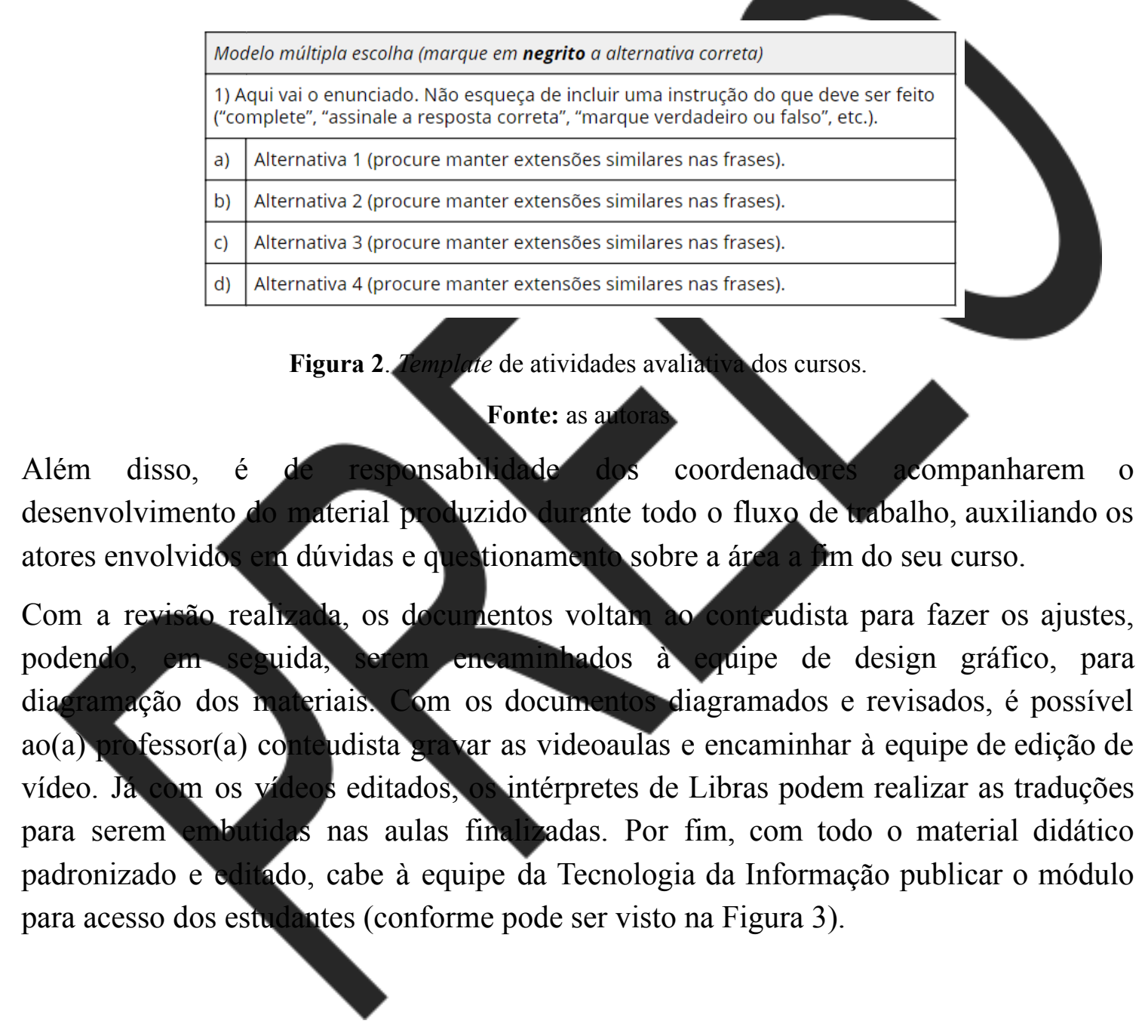

\footnotetext{
${ }^{4}$ As atividades são do tipo exercícios de marcar e de múltipla escolha, com autocorreção pelo Moodle.

${ }^{5}$ De acordo com o Guia de Orientações Gerais de Revisão (CUNHA; ALVES; DARIZ, 2020, p. 24): "O tamanho da alternativa gabarito e das alternativas distratoras deve manter equilíbrio, a fim de evitar que o(a) aluno(a), mesmo sem saber a resposta correta, acabe por marcar a alternativa maior".
} 


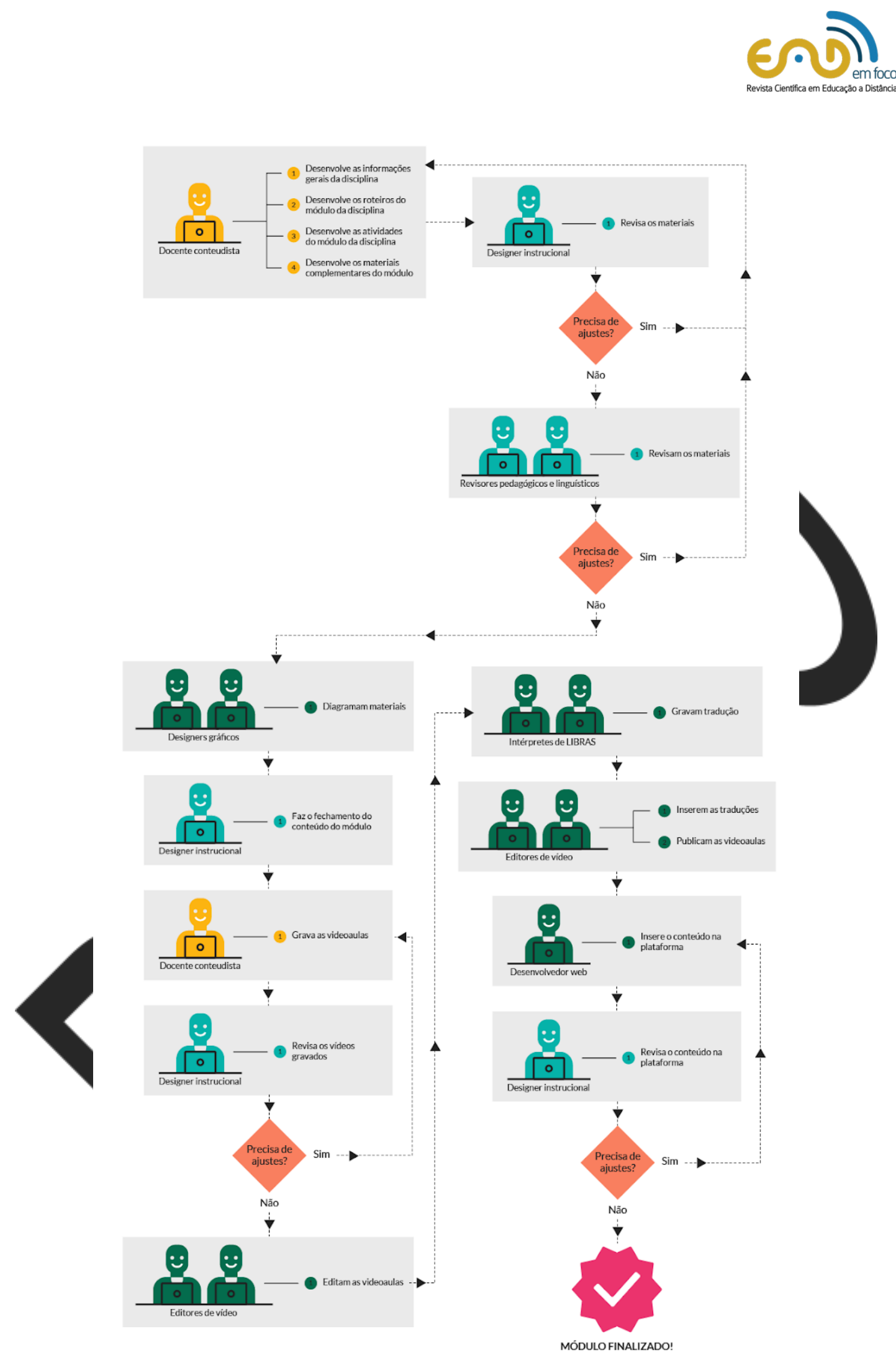

Figura 3. Fluxo de trabalho, equivalente a um módulo de uma disciplina.

Fonte: as autoras

Os Cursos de Formação Inicial e Continuada foram elaborados dentro da carga horária (que fica em torno de 180 horas a 240 horas, dependendo do curso e da área) mínima 


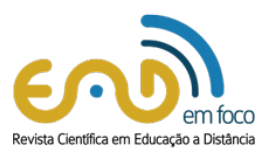

sugerida pelo Guia PRONATEC de Cursos FIC e, por esse motivo, divididos em diversas disciplinas, a fim de cumprir essa carga horária. Isso evitou que as equipes de pós-produção (design gráfico, edição de vídeo e interpretação de libras) ficassem paradas e que fosse possível publicar gradativamente as disciplinas dos cursos aos estudantes já matriculados. Assim, foi definida uma modelagem de produção dividida por módulos, ou seja, a primeira entrega é a do Módulo 1, a segunda do Módulo 2, e assim sucessivamente. Dessa forma, enquanto o conteudista trabalhava no Módulo 2, por exemplo, as equipes de produção já tinham material para editar do Módulo 1, já entregue pelo professor.

A Figura 4 é um excerto do cronograma total do projeto, dividido per disciplinas e módulos, sendo M1 = Módulo 1, M2 = Módulo 2, e assim sucessivamente. Os números do topo representam os dias da semana, de segunda a sexta-feira. Por exemplo; dos dias 1 a 4, era realizada a escrita do conteúdo (roteiro, slides atividades) referente ao Módulo 1. No dia seguinte (5), era feita a revisão deste conteudo por parte do designer instrucional. Nas próximas semanas, fluxo prosseguia com os demais membros da equipe.

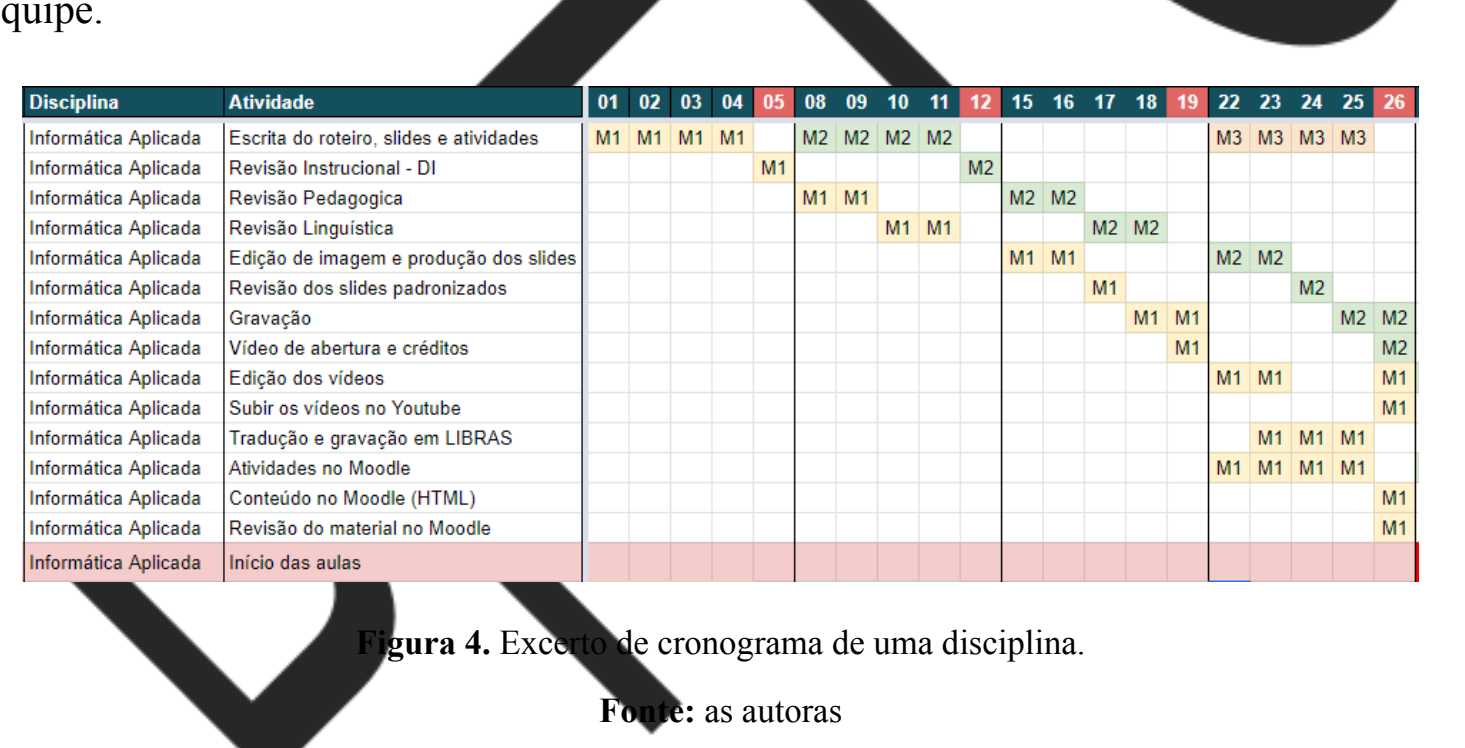

Um módulo, normalmente, é desenvolvido no período de um mês, passando por todo o processo proposto neste fluxo de trabalho. É importante ressaltar que, enquanto um módulo seguia para as etapas finais após a gravação (edição dos vídeos, tradução em Libras e inserção no AVA), as demais equipes já estavam trabalhando em outros módulos com o objetivo de otimizar o processo de produção.

Caso um dos materiais desenvolvidos precisasse voltar a uma etapa anterior do fluxo, por conta de novas revisões ou problemas de gravação das videoaulas, por exemplo, o cronograma de trabalho era alterado para recomeçar o fluxo da etapa que era necessária refazer. 
Além dos profissionais citados acima, é importante destacar que cada equipe multidisciplinar possuía um coordenador, responsável pelo acompanhamento e cumprimento dos prazos, bem como a revisão das atividades realizadas. As equipes também possuíam professores mediadores que, no entanto, não participam desse processo de desenvolvimento dos materiais didáticos. Os mesmos só começam suas atividades após o curso estar pronto e disponível na plataforma ou Ambiente Virtual de Aprendizagem, realizando a mediação e o acompanhamento dos discentes selecionados para cursarem os cursos FIC. Além dos professores mediadores, o Coordenador de Curso e a equipe de desenvolvedores Web também seguem stas atividades após o término do fluxo de trabalho, atuando no suporte e relação ao curso já produzido.

\section{Considerações finais}

O Instituto Federal de Educação, Ciência e Teçologia Sul-rio-grandense-oferta, desde 2007, cursos na modalidade EaD dentro do estado do Rio Grande do Sur de maneira ampla e em vários graus, ou seja, cursos técnicos, superiores (graduacão, tecnólogo e licenciatura) e de pós-graduação.

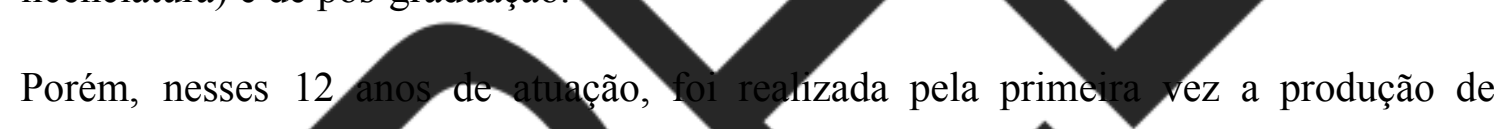
materiais bem como ofertados cursos EaQ do tipo de Fornação Inicial e Continuada. Observa-se que a implementação de cursos de Educação a Distância é sempre um grande desafio para as instituiçôes de ensino. Ofertar essa nova modalidade de ensino em un período de pandemia, onde o trabahtho se encontra $100 \%$ de forma remota, foi para equipe multidisciplinar uma nova maneira de aprender e desenvolver configuracões inovadoras de trabalho, com foco principalmente na busca por práticas pedagógicas que garantam sua eficiência e eficácia.

Dessa forma, fui preciso a construção desse fluxo e do acompanhamento da produção mediada por esse fltxo, pensando que os cursos FIC seriam ofertados para o mais variado tipo de públioo em relação à faixa etária, localização e grau de estudo. Garantir o aprendizado autônomo desses estudantes constitui-se em um desafio pedagógico gratificante para a equipe.

Com a possibilidade da criação de novos cursos FIC na modalidade EaD, surgiram inquietações que motivam a reflexão de como tornar esse fluxo de trabalho mais eficaz. Algumas questões de reflexão são: Como melhorar esse fluxo? Quais serão as etapas e os encadeamentos realizados por outros institutos e outros projetos? Como se formam e se organizam as equipes multidisciplinares que desenvolvem os cursos de Formação Inicial e Continuada na modalidade a distância? Essas inquietações constantes da equipe da CPTE colaboram para uma otimização desses processos e justificam-se em função 
do aumento da demanda e consequente valorização dos cursos $\mathrm{EaD}$, que já estava ocorrendo, mas que foi potencializada durante a pandemia.

Ao final da elaboração dos primeiros cursos, os coordenadores foram reunidos para trocar experiências com base nos relatos dos membros das equipes. Em relação ao tempo de desenvolvimento das atividades, o único relato negativo foi por parte dos professores conteudistas que, ao mesmo tempo que tinham que roteirizar o Módulo 2, por exemplo, tinham que, na mesma semana, gravar o Módulo 1. Assim, foi discutida pela equipe gestora uma nova proposta de cronograma, movendo a etapa de gravação para o período após a escrita de conteúdo. Outra obseryação interessante trazida pela equipe foi a dos intérpretes, que relataram ter dificuldade em fazer a tradução em vídeos nos quais os professores falavam muito rápido. Para sanar esta dificuldade, foi realizada uma reunião com os professores e a equipe de libras, onde puderam se conhecer trocar experiências, elucidando essa questão.

Além disso, a fim de receber um feedback dos discentes, os alunos de cada curso deveriam, de forma anônima, avaliar a experiêncta com os cursos en diferentes eixos, como seu desempenho (autoavaliação), qualidade do conteúdo e material do curso e usabilidade da plataforma. O certificado de conclusão do curso apenas era gerado após o preenchimento deste formulário de avaliação. Ao compilar os dados foi possível observar que grande parte dos alunos está satisfeita com a propostados cursos, bem como a qualidade dos materiais produzidos. Dentre as críticas, as principais envolviam a ausência de materiais complementares, è maioria links externos que, fora do controle da equipe dos FIC, sáam do ar, e a qualidade do áudio de algamas videoaulas. Quanto a esta últina, ja era esperada, pois os-vídeos foram gravados de forma caseira pelos contetdistas, com microfones e computadores prôpríos. As sugestões encaminhadas pelos a unos tambén foram discutidas e incorporadas ao fluxo de trabalho e formações feitas junto às equipes multidisciplinares e professores conteudistas, sempre a fim de melhorar os processos de desenvolvimento, ensino e aprendizagem.

\section{Referências}

ALONSO, K. M.; SILVA, D. G. A Educação a Distância e a Formação on-Line: O Cenário das Pesquisas, Metodologias e Tendências. Educação \& Sociedade, v. 39, n. 143, p. 499-514, 2018.

BEHR, A.; MILL, D. Gestão estratégica da educação a distância. In: MILL, D. et al. (Ed.). Dicionário crítico de educação e tecnologias e de educação a distância. São Carlos: UFSCar, 2018. 
BRASIL. Lei $\quad \mathbf{n}^{\mathbf{9}} \mathbf{9 . 3 9 4 / 9 6}$ 1996. Disponível em: http://portal.mec.gov.br/seed/arquivos/pdf/tvescola/leis/lein9394.pdf. Acesso em: 21 out 2020.

BRASIL. Lei $\mathbf{n}^{\mathbf{0}}$ 10.098. 2000. Disponível em: $<$ https://www.presidencia.gov.br/ccivil_03/Leis/L10098.htm>. Acesso em: 14 set 2021.

BRASIL. Decreto n. $^{\text {- }}$ 2.494. 1998. Disponível em: http://portal.mec.gov.br/seed/arquivos/pdf/tvescola/leis/D2494.pdf.Acesso em: 25 out 2020.

BRASIL. Decreto n. $^{\mathbf{5 . 6 2 2}}$ 2005. Disponivel em: http://www.planalto.gov.br/ccivil_03/_ato2004-2006/2005/decreto/d5622.htm. Acesso em: 23 out 2020 .

BRASIL. Decreto
http://www.planalto.gov.br/ccivil_03/_at 2004-2006/2006/decreto/d5773.htm.
em: 23 out 2020. http://www.planalto.goybr/ccivil_03/ato2007-2010/2007/decreto/d6303.htm. Acesso
em: 23 out 2020 .

BRASIL. Referenciais de Qualidade para Educação Superior a Distância. 2007. Disponível em: http://portal.mec.gov.br/seed/arquivos/pdf/legislacao/refead1.pdf. BRASIL. Ministério 19 da Edueação. Disponível em: http://portal.mec.gov br/component/content/article?id=12823:o-que-e-educacao-a-distan cia. Acesse em: 10 set. 2021.

BUENO, J.; PASCAOALINO, Q. Gestão da qualidade na educação a distância. In: MILL, D. et al. (Ed.). Dicionário crítico de educação e tecnologias e de educação a distância. São Carlos: USCar, 2018.

CAROLEI, P. Processo de criação de hipertextos e atividades. In: Design instrucional para cursos online. 2019. São Paulo: Artesanato Educacional.

CHAUHAN, J. Enhancing MOOC with Augmented Reality, Adaptive Learning and Gamification. Published in: MOOCs, Innovation and Technology in Education (MITE), 3rd International Conference on. 2015.IEEE. 
COHEN, A.; HOLSTEIN, S. Analysing successful massive open online courses using the community of inquiry model as perceived by students. Journal of Computer Assisted Learning, p. 1-13, 2018.

CRUZ, J. R.; LIMA, D. da C. B. P.. n. 13-TRAJETÓRIA DA EDUCAÇÃO A DISTÂNCIA NO BRASIL: POLÍTICAS, PROGRAMAS E AÇÕES NOS ÚLTIMOS 40 ANOS. Jornal de Políticas Educacionais, v. 13, 2019.

CUNHA, A. P. de A.; ALVES, C. V. P.; DARIZ, M. R. (org.). Guia de orientações gerais de revisão: curso de formação inicial e continuada (FIC).-Instituto Federal de Educação, Ciência e Tecnologia Sul-rio-grandense. Pelotas: WrSul, 20

FILATRO, A.; CAIRO, S. Produção de conteúdos educacionais. São Paulo: Saraiva, 2015.

HACK, J. R. Introdução à educação a distâncià 2011. Florianópdlis: LLV/CCE/UFSC.

IFSUL. Regulamento do Funcionamento dos cursos de extensão Livres e/ou de Formação Inicial e Continaadą ou Qualificação Rrofissional (FIC), do Instituto Federal de Educação, Ciência e Tecnologia Sul-kio-gràndense. 2016. Disponível em: http://www.ifsul.edu.br/documentos-ext/iten/305-regulamento-cursos-fic-e-formularios. Acesso em: 19 out 2020. IFSUL. Editais PROEN/PROEXT no 26, 27, 28, 29, 32, 34 e 37/2020. 2020. Disponível-em: http//editais.ifsul.edu.br/index.php?c=lista\&id=1367. Acesso em: 17 out 2020.20 MERCADO, L. P. Equipe multidisciplinar em educação a distância. In: MILL, Daniel et al. (Ed.) Dicionário crítico de educação e tecnologias e de educação a distância. FSCar, 2018

MORAN, J. M. que é educação a distância. Site pessoal do autor, São Paulo, artigo atualizado 2002 Disponível em: http://www2.eca.usp.b./moran/wp-content/uploads/2013/12/dist.pdf. Acesso em: 17 out 2020.

MUNHOZ, A. S. Projeto instrucional para ambientes virtuais. São Paulo: CENGAGE Learning, 2016.

MUÑOZ, R. A experiência internacional com os impactos da COVID-19 na educação. Nações Unidas Brasil, 2020. Disponível em: https://brasil.un.org/pt-br/85481-artigo-experiencia-internacional-com-os-impactos-da-c ovid-19-na-educacao. Acesso em: 10 set 2021. 


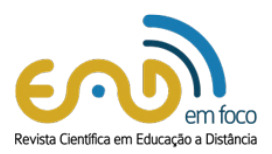

NAKAMURA, W. T.; DE OLIVEIRA, E. H. T.; CONTE, T. Usability and user experience evaluation of learning management systems-a systematic mapping study. In: International Conference on Enterprise Information Systems. Scitepress, 2017. p. 97-108.

NETO, A. J. M. et al. Visão sistêmica e Administração. São Paulo: Saraiva Educação SA, 2017.

ORTH, M. A.; OTTE, J.; MEIRELES, L. O. R. Políticas públicas de educação a distância pela universidade aberta do brasil: a experiencia do Instituto Federal sul-rio-grandense. Roteiro, v. 39, n. 1, p. 147-170, 2014.

RIBEIRO, L. O. M.; CATAPAN, A. H. Plataformas MOOC e Redes de Copperação na EAD. Revista de Educação a Distância, v. 5, n. 1, p.45-62. 2018.

RICHARDSON, R. J. et al. Pesquisa secial: métodos e técnicas. 14. Reimpr. São Paulo: Atlas, 2012.

SANCHOTENE, I. J. .; ENGERS, P. B. ; RUPPENTHAL, R. .; HHA, P. . Competências Digitais Docentes e o Processo de Ensino Remoto Durante a Pandemia da Covid-19. EaD en Foco, v. 10, n. 3,12 jan. 2021. SILVA, R. S. da. Gestão de EaD: educação a distância na era digital. São Paulo:
Novatec Editora,2017.

VIDAL, E. M.; MAIA J. E. B. Introdução à educação a Distância. Fortaleza: Editora

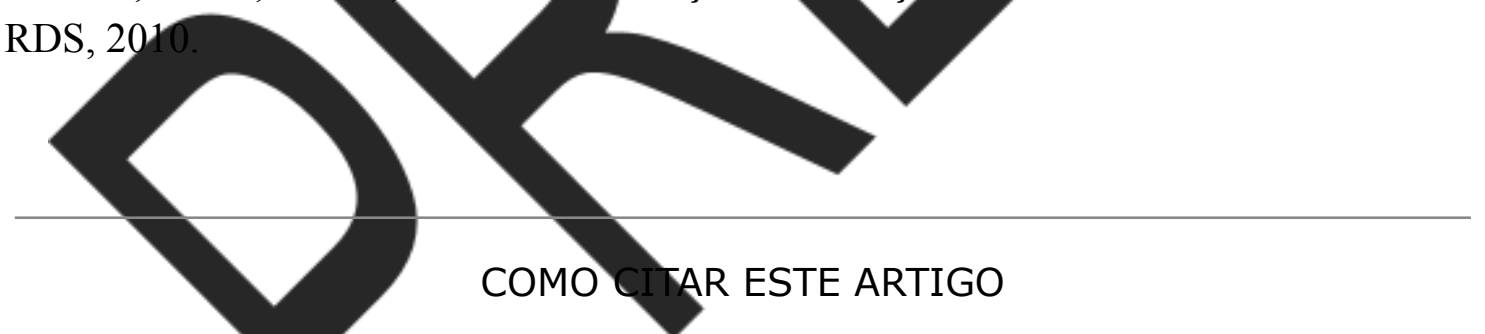

ABNT: Gugliano, B. F.; MOREIRA, M. I. G.; BEHLING, A. S. Desenvolvendo Cursos de Formaçáo Inicial e Continuada (FIC) EaD em Regime de Trabalho Remoto: Relato de Experiência. EaD em Foco, v. 11, n. 1, e1439, 2021. doi: https://doi.org/10,18264/eadf.v11i1.1439 